\title{
Abstract
}

This paper is devoted to the notion of time and its derivation from a more original notion of process, as it is developed by Whitehead. The importance of the notion of process is known by to have been a constant concern in Whitehead's philosophical development from his earlier works in the fields of mathematics, logic and epistemology, passing through the philosophy of nature and reaching the metaphysical works. Time proves to be a question intimately correlated to process in Whitehead's multi-faceted approach. His final achievements concerning this question show that process is seen as a more fundamental aspect than time in order to understand what exists. Process is further divided into concrescence and transition, and also contrasted to "reality". The paper aims to discuss these notions and their mutual relevance. The scope is to provide a clue for understanding Whitehead's elusive conception of cosmology in terms of creativity and passage.

\section{The Time of the Actual Entity}

The study of the processuality proper to a single actual entity, as a process of concrescence, probably represents the most deeply studied aspect of the theme of temporality in Whitehead's philosophy. Without ignoring the utility of a number of the essays now available on the topic, it will be nevertheless useful to give an overall structural description of this issue. In the light of Whitehead's concept of subjectivity, the aspect to be described in the first place is the notion of process as the emergence of a subject and its individuation. It is necessary to investigate the temporal structure of this process.

In terms of the articulation of the temporal dimensions, theme which I systematically develop below, the single process of concrescence is identified by Whitehead with the present. The present is, in other words, the effect of the processual experiential activity of a subject placed in a concrescence, which means both the passage from publicity to privacy, and the synthetic reaction of the sub- 
ject to the multiplicity of the world. From the point of view of Whitehead's conception of temporality, this means that time depends on the experiential activity of the subject, and can therefore be characterised as temporalisation. This temporalizing activity, however, is in its turn conditioned, since the subject effecting the temporalisation is in itself a product of temporalisation, and produces itself exclusively as structurally affected by time, which means it is not extra-temporal. The problem whether the actual entity be within or outside time has been discussed at length: my answer is that the actual entity is neither within nor without time, but is time, in the sense that it institutes time through the activity of temporalisation, but does not transcend this activity, being on the contrary its effect. This thesis cannot be clarified unless one deepens the nature of the temporal/temporalizing subject in terms of emergence and finitude. In Whitehead's conception, the two aspects are inseparably connected, and cannot be isolated except at the price of the loss of their intelligibility.

To speak of the emergence of a subject within its own temporal process means to speak of the duplicity of determination of subjectivity, and, correlatively, of temporality. The subject is, according to Whitehead, always subject/superject. It is the structural unity of its two opposite determinations: it is at once cause and effect of itself. ${ }^{1}$ Whitehead shows this notion to be intrinsically related to experience, in a passage which in its conciseness expresses the sense in which PR relates time, subject, and experience. Whitehead writes:

The more primitive types of experience are concerned with sense-reception, and not with sense-perception. This statement will require some prolonged explanation. But the course of thought can be indicated by adopting Bergson's admirable phraseology, sense-reception is 'non-spatialized', and sense-perception is 'spatialized'. In sense-reception the sensa are the definiteness of emotion: they are emotional forms transmitted from occasion to occasion (Whitehead 1978, 113-114).

As Whitehead himself remarks, this thesis requires a prolonged explanation, which is what will be undertaken here. Notice that every process possesses a dual structure, according to which there are two components, one receptive and one reactive. The process itself is the articulation of this dual structure. Now, the fact that each single process is dual raises the question of the relationship between the two modes. It is possible to say that, generally speaking, this relationship is usually interpreted in terms of successive phases: each phase of

1 What Whitehead also says "to be causa sui". On this subject see Whitehead 1978, 149-51; 220 -222. The meaning of this expression is clarified in 222 as follows: "Self-realisation is the ultimate fact of facts. An actuality is self-realising, and whatever is self-realising is an actuality. An actual entity is at once the subject of self-realisation, and the superject which is self-realised". 
concrescence is followed by a phase of transition, so it is possible to represent the succession of actual entities in terms of an alternated succession of two distinct modes or segments, in this way: concrescence-transition-concrescencetransition, and so on. Recall, however, that each actual entity constitutes itself through other actual entities. From the point of view of the process, what does this consideration imply? It implies, in line with Whitehead's rejection of the fallacy of simple location or presence, that these two faces of the process are not two totally different and independent facts. The thesis I want to demonstrate in this paper is that concrescence and transition are indeed distinct, i.e., distinguished, but not separated and not independent.

I do not intend to identify concrescence and transition. I want to keep them distinguished. This distinction is important in order to clarify the process of temporalisation. However, what I intend to show is that concrescence and transition are two dual, reciprocal modes of processuality itself, and not two independent segments of a linear succession of time. To show this interdependence between the two "phases" should allow me to demonstrate what type of cohesion does exist in the succession of actual entities which characterises the "history" of the total subject. In order to clarify my interpretative thesis, I would like to start from the following text from Process and Reality, which has the advantage of putting in relation the two modalities of the process in a clear way:

There are two species of process, macroscopic process, and microscopic process. The macroscopic process is the transition from attained actuality to actuality in attainment; while the microscopic process is the conversion of conditions which are merely real into determinate actuality. The former process effects the transition from the 'actual' to the 'merely real'; and the latter process effects the growth from the real to the actual. The former process is efficient; the latter process is teleological. The future is merely real, without being actual; whereas the past is a nexus of actualities. The actualities are constituted by their real genetic phases. The present is the immediacy of teleological process whereby reality becomes actual. The former process provides the conditions which really govern attainment; whereas the latter process provides the ends actually attained. The notion of 'organism' is combined with that of 'process' in a twofold manner. The community of actual things is an organism; but it is not a static organism. It is an incompletion in process of production. Thus the expansion of the universe in respect to actual things is the first meaning of 'process'; and the universe in any stage of its expansion is the first meaning of 'organism'. In this sense, an organism is a nexus. Secondly, each actual entity is itself only describable as an organic process. It repeats in microcosm what the universe is in macrocosm. It is a process proceeding from phase to phase, each phase being the real basis from which its successor proceeds towards the completion of the thing in question. Each actual entity bears in its constitution the 'reasons' why its conditions are what they are. These 'reasons' are the other actual entities objectified for it (Whitehead 1978, 214). 
Let us try to bring the meaning of this quotation to light. The fundamental datum to be considered is the fact that each process of concrescence starts from what it receives, that is to say, from what it inherits from other actual entities, which are called "objectified". This means that the process of concrescence is based on the process of transition. In fact, transition is the modality which allows one actual entity to be efficacious for another. Obviously, this is reciprocal: only by means of the new concrescence can the potential efficacy of the objectified actual entities produce a new actual entity. It is only because a new process re-enacts the past that the past can be efficacious on the present, that is, the past's future. There is thus a reciprocal relationship of determination. The transition produces what, in Whiteheadian terms, is called the passage from the actual to the merely real, while the concrescence produces the reciprocal effect, the passage from the merely real to the actual. Thus, concrescence and transition do not take place one after the other, as it were, but together, and in a certain sense simultaneously.

The relationship between concrescence and transition is connected to that between a single actual entity and the world, and is reciprocal. The thesis is explicitly stated by Whitehead in the passage quoted above. There is thus, at the level of temporality, a confirmation of the dual and reciprocal model, which is at work on the level of subjectivity. We can, in this respect, recall the metaphor used by Merleau-Ponty in his late works: the process of expansion and contraction, systole and diastole. In this case too, the condition of being a relationship between the single and the totality is more fundamental, for each process, than the one of succession. Clearly this analysis poses some problems for common sense. But the opposite position is grounded on the separation of the substances, and their spatiotemporal individuation, which Whitehead rejects.

We must notice furthermore that, according to Whitehead, the temporal "places" of the past, present, and future, are determined with respect to the experiential activity. In other words, they do not have an absolute position and an autonomous subsistence. How can this interpretative thesis be corroborated? It seems necessary to analyse all the aspects entailed in the concept of temporalisation. We must then, in the first place, render explicit the structural characters of the concept of time progressively determined by Whitehead's analysis.

\section{The Structure of Temporalization: the Criticism of the Abstract Notion of Time}

In the first place, it is necessary to give an overall account of the notion of time as process according to Whitehead. Already in The Concept of Nature, Whitehead 
declares that the general concept of time, at least the one proper to the natural sciences, is an abstract concept. His position becomes progressively more explicit and more detailed as his more speculative works appear. Whitehead finally no longer wants to adopt the term "time" since it is conditioned by the comprehension proper to the materialist sciences he has been criticising in his epistemological works. This statement entails several different theses which must be distinguished: "true" time, that is, the time from which the materialist conception of nature abstracts, ${ }^{2}$ is characterised by its being extended and not punctiform, by its being a succession, further determined as passage, and by its being undetermined, that is, not deterministically conditioned, and finally by its being finite.

The criticism of the instantaneous concept of time has already been discussed in many works. Whitehead in any case reiterates this criticism until the end of his scientific life. ${ }^{3}$ To the notion of time as succession of punctiform and reciprocally unrelated instants, Whitehead at first opposes the one based on time as extension and duration. Successively, he further elaborates this concept, by remarking that the concept of duration and the concept of extension do not express explicitly enough what is the decisive aspect to be assigned to temporality: its passing. This implies the need to better clarify the processual condition of time. The aspect which must be proven to be secondary ${ }^{4}$ is the extensionality of time. It follows that it is not enough to substitute the notion of instant with the notion of extended duration to adequately account for time: time must be differently qualified. This revision also entails the need to explain why everyday experience thinks of the temporal dimensions in terms of separated places. The mistake does not consist in conceiving this abstract time, but in its ontological absolutisation. ${ }^{5}$ But what, according to Whitehead, is the time of common sense, in the light of the speculative investigation?

2 See Whitehead 1985a, 183: "Time is sheer succession of epochal durations".

3 See Whitehead 1968, 199: "There is a fatal contradiction inherent in the Newtonian cosmology [...] Now assuming this Newtonian doctrine, we ask-What becomes of velocity, at an instant? Again we ask-What becomes of momentum at an instant? These notions are essentials for Newtonian physics, and yet they are without any meaning for it". See also Whitehead 1968, 207: "It is nonsense to conceive of nature as a static fact, even for an instant devoid of duration. There is no nature apart from transition, and there is no transition apart from temporal durations. This is the reason why the notion of an instant of time, conceived as a primary simple fact, is nonsense". 4 Secondary does not mean inauthentic. According to Whitehead, on the contrary, spatialization and temporalisation are two aspects of processuality. What becomes less relevant for Whitehead is the need to oppose, in the wake of Bergson's works, time and space.

5 See Whitehead 1968, 36-37: "The notion of potentiality is fundamental for the understanding of existence, as soon as the notion of process is admitted. If the universe be interpreted in terms 


\section{The Reification of Time}

In The Concept of Nature, Whitehead shows that the scientific concepts of space and time are operative abstractions, performed in connection to effective experience. Space and time are necessary tools for the cognitive, and before that existential, operations characterising the life of the subject. ${ }^{6}$ One could lead no normal life if one could not orient oneself according to a fixed and objective system of coordinates. ${ }^{7}$ The constitution of an objective structure of space and of time obeys vital needs, and is effectuated already in the simplest of the existential activities. Language, and the symbolic systems, simply perfect this attitude, already traceable at the animal level of behaviour.

If we understand that the time and space of common sense are abstractive operations, not mirroring an immediately given reality, then we can trace their origin without falling into the error of a metaphysical hypostatisation. Whitehead very clearly explains this duplicity of time (and space) in several passages of Process and Reality. He furthermore distinguishes the genetic analysis of creativity, which deals with processuality, from the coordinate analysis, which deals with the logico-mathematical aspects of what is created. He writes, for example:

of static actuality, then potentiality vanishes. Everything is just what it is. Succession is mere appearance, rising from the limitation of perception. But if we start with process as fundamental, then the actualities of the present are deriving their characters from the process, and are bestowing their characters upon the future. Immediacy is the realisation of the potentialities of the past, and is the storehouse of the potentialities of the future. Hope and fear, joy and disillusion, obtain their meaning from the potentialities essential in the nature of things. We are following a trail in hope, or are fleeing from the pursuit in fear. The potentialities in immediate fact constitute the driving force of process".

6 The same thesis is repeated in Whitehead 1978, 87: “The 'objectifications' of the actual entities in the actual world, relative to a definite actual entity, constitute the efficient causes out of which that actual entity arises; the 'subjective aim' at 'satisfaction' constitutes the final cause, or lure, whereby there is determinate concrescence; and that attained 'satisfaction' remains as an element in the content of creative purpose. There is, in this way, transcendence of the creativity; and this transcendence effects determinate objectifications for the renewal of the process in the concrescence of the actualities beyond that satisfied superject. Thus, an actual entity has a threefold character: (i) it has the character 'given' for it by the past; (ii) it has the subjective character aimed at in its process of concrescence; (iii) it has the superjective character, which is the pragmatic value of its specific satisfaction qualifying the transcendent creativity".

7 See this passage from Whitehead 1978, 170, very similar to the quotation from Claudel to be found two times in VI: "Every statement about the geometrical relationships of physical bodies in the world is ultimately referable to certain definite human bodies as origins of reference. A traveller, who has lost his way, should not ask, Where am I? What he really wants to know is, Where are the other places? He has got his own body, but he has lost them". 


\begin{abstract}
Physical time makes its appearance in the 'coordinate' analysis of the 'satisfaction'. The actual entity is the enjoyment of a certain quantum of physical time. But the genetic process is not the temporal succession: such a view is exactly what is denied by the epochal theory of time. Each phase in the genetic process presupposes the entire quantum, and so does each feeling in each phase. The subjective unity dominating the process forbids the division of that extensive quantum which originates with the primary phase of the subjective aim. The problem dominating the concrescence is the actualization of the quantum in solido. [...] There is a spatial element in the quantum as well as a temporal element. Thus, the quantum is an extensive region. This region is the determinate basis which the concrescence presupposes. This basis governs the objectifications of the actual world which are possible for the novel concrescence. The coordinate divisibility of the satisfaction is the 'satisfaction' considered in its relationship to the divisibility of this region (Whitehead 1978, 283).
\end{abstract}

From passages like this it is possible to conclude that the mathematisation of reality serves pragmatic purposes. It is meaningful to ask what the measurable structure of reality is. It is not meaningful, however, to ask what the measure of a single process is. This question is exactly re-introducing the metaphysical presuppositions that the whole Whiteheadian work tries to unmask and reject. ${ }^{8}$ The static and totally unfolded structure which, in McTaggart's terms, is called BSeries, that is, the calendarial time of the dates, is what lends itself to measurements and objective evaluations. But this structure is derivative with respect to the processuality of the actual entities, as this passage, extracted from the fourth part of Process and Reality, shows:

A duration is a complete locus of actual occasions in 'unison of becoming', or in 'concrescent unison'. It is the old-fashioned 'present state of the world'. In reference to a given duration, $\mathrm{D}$, the actual world is divided into three mutually exclusive loci. One of these loci is the duration D itself. Another of these loci is composed of actual occasions which lie in the past of some members of D: this locus is the 'past of the duration D'. The remaining locus is composed of actual occasions which lie in the future of some members of $\mathrm{D}$ : this locus is the 'future of the duration D' (Whitehead 1978, 320).

What immediately results from this quotation is the fact that the present proper to the duration is devoid of dynamism. It is the present considered ex post, or, to use an expression typical of Merleau-Ponty's philosophy, it is the present seen from nowhere, with a panoramic, kosmotheoretic gaze. The same can be said for past and future. What past, present and future as extended lack, is their most intrinsic quality, their "sense of being". Whitehead expresses this difference by speaking of a processual time as atomic or epochal. He does not oppose the

8 Whitehead 1985a, 183: "The epochal duration is not realised via its successive divisible parts, but is given with its parts". 
time of physics and the time of process metaphysics as two distinct substances, since on the contrary he sees a derivation of the former from the latter; but he wants to avoid reducing one to the other. ${ }^{9}$ It is therefore necessary to analyse closely the way in which Whitehead analyses the dimensions of time in what appears to be their sense of being. It is in fact possible to show that Whitehead, in his own way, has studied the problem in a way which is original while still close to the phenomenological one.

\section{Time and Experience}

If one can say that experience, according to Whitehead, cannot take place except temporally, and that it is temporally conditioned, now it is possible to evaluate the reciprocal statement. There is temporality insofar as there is experiential activity. The determination of the sense of being proper to the temporal dimensions is linked, according to Whitehead, to this fact. In particular, Whitehead connects the articulation of the dimensions of time to the two perceptive modalities, Causal Efficacy and Presentational Immediacy, which are thematised in Symbolism and in Process and Reality, and which constitute the symbolic reference. As Whitehead writes in Symbolism,

Time is known to us as the succession of our acts of experience, and thence derivatively as the succession of events objectively perceived in those acts. But this succession is not pure succession; it is the derivation of state from state, with the later state exhibiting conformity to the antecedent. Time in the concrete is the conformation of state to state, the later to the earlier; and the pure succession is an abstraction from the irreversible relationship of settled past to derivative present (Whitehead 1985b, 35).

In order to bring to light Whitehead's position in all its complexity I must at this point turn to a detailed analysis of his position.

\section{The Present}

The process of concrescence is the place of the present. The present is not an abstract space among other abstract spaces, in turn products of a segmentation ex-

9 Whitehead 1985a, 185: "Time is atomic (i.e., epochal), though what is temporalized is divisible". Notice the presence of the adjective form deriving from the substantive temporalisation in a book dating 1925. 
ternal and extraneous to the flux of time and the becoming of existence: the present is the place in which the subject constitutes itself. It is because the present is the locus of this activity that it is what it is. Whitehead clearly expresses this thought in Modes of Thought:

Actuality is the self-enjoyment of importance. But this self-enjoyment has the character of the self-enjoyment of the one self. The most explicit example of this is our realization of those other actualities, which we conceive as ourselves in our recent past, fusing their self-enjoyment with our immediate present (Whitehead 1968, 161).

It follows that the present is not a point on a straight line but is characterised by its internal dialectical dynamic. Therefore, not only is the present not an instantaneous point, not only is it not simply an extended but static duration: the present is not even a linear passage, a natural event that would "take place" in order to happen. The present is insofar as it is a dialectical dynamic proper to experience. ${ }^{10}$ The present is the place of the articulation of the temporal dimensions. It is the place of the very happening of the temporalizing experience. This amounts to saying, echoing Merleau-Ponty's characterisation of space, that it is time that makes itself by itself, creates itself. It is an exteriority which turns upon itself and hollows out an interiority. This means, in Whiteheadian terms, that the present is the passage from the publicity of the world to the privacy of the subject. It is a cyclic whirl, which rhythmically winds round itself to then undo itself once again. But what is properly speaking the structure of this present? It is necessary to recur to the analysis offered in Adventures of Ideas in order to bring to the fore the meaning of Process and Reality. Here, in a wonderful passage, Whitehead writes as follows

If we keep ourselves to this short-range intuition, assuredly the future is not nothing. It lives actively in its antecedent world. Each moment of experience confesses itself to be a transition between two worlds, the immediate past and the immediate future. This is the persistent delivery of common-sense. Also this immediate future is immanent in the present with some degree of structural definition. The difficulty lies in the explanation of this immanence in terms of the subject-object structure of experience. In the present, the future occasions, as individual realities with their measure of absolute completeness, are non-existent. Thus, the future must be immanent in the present in some different sense to the objective immortality of the individual occasions of the past. In the present there are no individual occasions belonging to the future. The present contains the utmost verge of such realized individuality. The whole doctrine of the future is to be understood in terms of the account of the process of self-completion of each individual actual occasion. This process can be shortly characterized as a passage from re-enaction to anticipation. The in-

10 Obviously, to speak of experience does not entail presupposing a single separated subject. 
termediate stage in this transition is constituted by the acquisition of novel content, which is the individual contribution of the immediate subject for the re-shaping of its primary phase of re-enaction into its final phase of anticipation. This final phase is otherwise termed the 'satisfaction', since it marks the exhaustion of the creative urge for that individuality. This novel content is composed of positive conceptual feelings become integrated with the physical prehensions of antecedent occasions, and thus yield propositions concerning the past. These propositions are again integrated and re-integrated with each other and with conceptual feelings, and yield other propositions. Finally propositions emerge concerning the constitution of the immediate subject. It belongs to the essence of this subject that it passes into objective immortality. Thus, its own constitution involves that its own activity in self-formation passes into activity of other-formation. It is by reason of the constitution of the present subject that the future will embody the present subject and will re-enact its patterns of activity. But the future individual occasions are non-existent. The sole immediate actuality is the constitution of the present subject which embodies its own necessity for objective immortality beyond its own immediacy of self-formation. This objective immortality is a stubborn fact for the future, involving its pattern of perspective re-enaction. The final phase of anticipation is a propositional realization of the essence of the present-subject, in respect to the necessities which it lays upon the future to embody it and to re-enact it so far as compatibility may permit. Thus, the self-enjoyment of an occasion of experience is initiated by an enjoyment of the past as alive in itself and is terminated by an enjoyment of itself as alive in the future. This is the account of the creative urge of the universe as it functions in each single individual occasion. In this sense, the future is immanent in each present occasion, with its particular relations to the present settled in various degrees of dominance. But no future individual occasion is in existence. The anticipatory propositions all concern the constitution of the present occasion and the necessities inherent in it. This constitution necessitates that there be a future, and necessitates a quota of contribution for re-enaction in the primary phases of future occasions. The point to remember is that the fact that each individual occasion is transcended by the creative urge, belongs to the essential constitution of each such occasion. It is not an accident which is irrelevant to the completed constitution of any such occasion (Whitehead 1967, 192-193).

It has been necessary to fully quote this passage at length since it contains a lot that needs to be carefully considered. From the reading of these lines some considerations emerge:

1. that the present is the place or locus of existence, and therefore that past and future exist only insofar as they are given to a present;

2. that, on the other hand, past and future are not nothing. On the contrary, they are dimensions of the present itself, and are so since the present is not eternity but passage, not unlimited but limited, that is, the present arises, passes, and dies, and this passage is due to the fact that the present is the modality by which a finite being exists; the present, in other words, is the mode of the temporally finite existence of a subject. 
3. It follows that also past and future are, at once, relative and absolute terms. They are relative because what is future in relation to a certain actual entity will be past for another. They are absolute, however, because their position with respect to that determined actual entity is what it is and cannot be changed by the actual entity. This is precisely what renders the past past and the future future: the past is past because its sense of being is that of having happened; reciprocally, the future is characterised by its having not happened yet, and of going to happen (sooner or later). For this reason, the objectivity of the past is distinguished by Whitehead from that of the future. The past possesses an objectivity of its own, which is proper to what has effectively happened, whereas this is not proper to the future. What is proper to the future is its imminence and its being an element of attraction for the present perspective: the present is in fact never neutral, but always in tension toward a future.

But this is not all. Past and future are not only the elements in which the present articulates itself, but are such insofar as the present constitutes their connection. According to what Whitehead writes in this passage-in so doing summarising the whole meaning of the conception of actual entity proposed in Process and Reality-the present is configured as the passage from "re-enaction" to anticipation. We must exactly understand what sort of passage this is, that is, whether it is a pure transition from a point to another in a path, or whether it possesses a very different nature.

Various considerations suggest that the second alternative is correct. In the first place, one must insist on the fact that the new process is what activates the passage. If the new process were not present, that is, if the actual entity were not characterised by its being an activity, there would be no creative advance. Here the Whiteheadian notion of causality is called into play, and it is necessary to discuss an aspect of it. If, in fact, Whitehead often recurs to the notion of efficient causation, this does not mean that the new process occurs only insofar as "generated" by means of "Causal Efficacy". It is rather the contrary: Causal Efficacy is the expression of the fact that the new process cannot take place unless in connection with its environment, into which the process finds itself, as it were, thrown, although being a project, to use the well-known Heideggerian expressions. This means that the new subject cannot purely and simply invent an ontological situation of its own, but simply reacts to what it finds as already constituted.

But on the other hand, if the process were not acting, were not action, there would be no past either. The past, in other words, is the outcome of the process of experience. The past is therefore given only insofar as it is constituted by the new present. The subject can either conform itself to the environment in which it finds its place, or it can react to and change it. Either choice depends on the pre- 
sent subject, which therefore cannot be determined only in relation to the initial conditions in which it arises. In this sense, Whitehead is an intransigent indeterminist.

It is in this connection that the role of the future is displayed. The future does not exist in itself. The future is the expression of the indeterminacy of the present. The future is possibility, it is the ontological expression of the fact that the new process is not deterministically conditioned by the past. If this were the case, there would properly be no future, but only a sheer repetition of what has already been, since the essence of the future is that of not being derivable from what precedes it. A mere, continuous and eternal repetition of the same is no future at all, because there is no change. It is not by chance that a completely deterministic world is a world in which the distinction between past and future is meaningless, since the direction of time (the so-called "arrow") is reversible. The future is, essentially, an anticipation of what has not been yet, and will not be exactly as it was anticipated. There could be no anticipation if the future totally conformed to its past. That the future is to conform to its past is always possible, but never necessary, since this possibility depends on the decision taken in the present process, which therefore introduces an element of unpredictability and novelty.

The future, thus, plays a role, but only insofar as it is future-for-a-present, future given as future to a present. That is, as Whitehead underlines repeatedly, insofar as it is not something subsisting autonomously. The same can be said for the past, so that there is a double determination of the past: the past is given as past only to a present, that is, is not a past in itself, but is given to a present as past, i.e., it is irreversibly gone, past. The determination of past and present is thus clearly shown: the past can be past only insofar as there is a present for which it represents the past; but this does not make the past present: it makes it only present as past. This double relationality of the past with respect to the present, which is the past's future, and reciprocally of the future, forces us to take a closer look at the way in which Whitehead determines these two temporal dimensions, in order then to examine the question, at which Whitehead hints at the end of the passage above quoted, as to what the creative push or urge is which transcends each single process of concrescence.

\section{Past and Future: Non-Linearity of Process}

As a matter of fact, Whitehead explicitly declares that the present does not exist as pure irrelative datum, but only as dynamic articulation. The extension of a duration is therefore clearly determined not in terms of simple, not further struc- 
tured, extensionality, but on the contrary in terms of an interconnection of the temporal dimensions. This is what renders time something different from space. As far as the future is concerned, Whitehead writes:

The past has objective existence in the present which lies in the future beyond itself. But the sense in which the future can be said to be immanent in occasions antecedent to itself, and the sense in which contemporary occasions are immanent in each other, are not so evident in terms of the doctrine of the subject-object structure of experience. It will be simpler first to concentrate upon the relation of the future to the present. The most familiar habits of mankind witness to this fact. Legal contracts, social understandings of every type, ambitions, anxieties, railway time-tables, are futile gestures of consciousness apart from the fact that the present bears in its own realized constitution relationships to a future beyond itself. Cut away the future, and the present collapses, emptied of its proper content. Immediate existence requires the insertion of the future in the crannies of the present (Whitehead 1967, 191).

The presence of the future in the present is evidently of an experiential nature, but not necessarily conscious. For the moment however we must in the first place deepen the logico-ontological structure of the codetermination between temporal dimensions, in order to support the thesis that the present is the place itself of this codetermination. We have said that it is necessary to avoid any hypostatisation or reification of the present, any naturalistic comprehension of it: the present is not a segment of the temporal line, but is what it is since it is the tension towards the future and connection to the past. Therefore, the present is not a univocal place, but receives from this correlation with the other two dimensions its definition, to the same extent that, reciprocally, the other two dimensions are defined in relation to the present. We thus obtain a complex structure of mutual interdependencies, which also explains the relativity of the temporal determinations: past and future are relative and perspectival terms, and the processual dynamic is a true activity of temporalisation and not the unfolding of something substantial. On the codetermination of the temporal dimensions Whitehead is explicit:

The future is immanent in the present by reason of the fact that the present bears in its own essence the relationships which it will have to the future. It thereby includes in its essence the necessities to which the future must conform. The future is there in the present, as a general fact belonging to the nature of things. It is also there with such general determinations as it lies in the nature of the particular present to impose on the particular future which must succeed it. All this belongs to the essence of the present, and constitutes the future, as thus determined, an object for prehension in the subjective immediacy of the present. In this way each present occasion prehends the general metaphysical character of the universe, and thereby it prehends its own share in that character. Thus, the future is to the present as an object for a subject. It has an objective existence in the present. But the 
objective existence of the future in the present differs from the objective existence of the past in the present. The various particular occasions of the past are in existence, and are severally functioning as objects for prehension in the present. This individual objective existence of the actual occasions of the past, each functioning in each present occasion, constitutes the causal relationship which is efficient causation. But there are no actual occasions in the future, already constituted. Thus, there are no actual occasions in the future to exercise efficient causation in the present. What is the objective in the present is the necessity of a future of actual occasions, and the necessity that these future occasions conform to the conditions inherent in the essence of the present occasion. The future belongs to the essence of present fact, and has no actuality other than the actuality of present fact. But its particular relationships to present fact are already realized in the nature of present fact (Whitehead 1967, 194).

In this passage Whitehead states, on the one hand, the symmetric interconnection of past and future with respect to the present; and yet also the diversity of the essential determination of each dimension. Past and future, in other words, if on the one hand are dimensions given only insofar as they are in relation to the present, on the other are differently given from one another. The past is, so to speak, the dimension of the "no more", the future of the "not yet". That which exists, exists only in the present mode. Only the present is actively existent, that is, it possesses, to use Whitehead's lexicon, "subjective immediacy". Past and future are only objectively; they cannot be considered in terms of subjective determinations, that is, they are not "actual" in the meaning Whitehead gives to this word. If therefore the present is the place of the codetermination of past and future, this complex relationship cannot be conceived in linear terms. As Whitehead here explicitly says, the future is imminent in the present. The same thing can be said, mutatis mutandis, for the past. ${ }^{11}$ This means that the future is present as future. In other words, the future is not if by "being" one understands the being of the present. However, the future is, the only way given to the future to be is that of being given as future to a present. Another aspect must be underlined: this mode of givenness of the future possesses the characteristic of being undetermined, while the one proper to the past is precisely its being completely determined and irrevocable: pereunt et imputantur, as Whitehead likes to say.

It would be impossible to say more explicitly that past and future depend on the experiential process and are not physical loci. Without it ever being explicitly said, Whitehead thus rejects the image of time in terms of a straight line. The image of the line is misleading since it implies that past and future are stages

11 In what follows I will constantly insist on the future, but the reader should always understand the possibility to transpose the argument to the past. I will speak about only one dimension for the sake of brevity of the analysis. 
of a linear path. In reality, the future is not given unless to a present which in turn is such only insofar as it has a relation with its own past. The immanence of the future in the present is the negation of the fact that the future is what the present is not. If one defines the present in opposition to past and future, then these two dimensions lose their meaning. This, in any case, does not imply, as a possible interpretation inspired by Levinas could suggest, that in thus conceiving of the future, it would lose its most specific and intrinsic character: what makes it the irruption of unexpected novelty. On the contrary, it is only by reason of the existence of a being who is able to institute the articulation of the temporal dimensions that the unexpected can take place. The conception of temporality expressed by Whitehead in his speculative works is therefore very clearly articulated in terms of an ontology of experience. There is no becoming, which is the true form of time, unless insofar as there is an experiencing subject. The nature of this subject, however, is not that proper to a transcendental subjectivity, but on the contrary the one proper to a subject emerging from its own experiential process, a subject which therefore not only is the origin of temporality, but is at the same time its effect. It is in this sense that we must understand the concept of becoming which grounds the whole metaphysics of process:

These various aspects can be summed up in the statement that experience involves a becoming, that becoming means that something becomes, and that what becomes involves repetition transformed into novel immediacy. This statement directly traverses one main presupposition which Descartes and Hume agree in stating explicitly. This presupposition is that of the individual independence of successive temporal occasions. [...] This presupposition of individual independence is what I have elsewhere called, the 'fallacy of simple location'. [...] The doctrine of the individual independence of real facts is derived from the notion that the subject-predicate form of statement conveys a truth which is metaphysically ultimate (Whitehead 1978, 136-137).

The interdependence of the temporal dimensions is the other side of the reciprocal relationality among actual entities. This consideration vindicates the thesis expressed at the beginning of this paper, according to which concrescence and transition are not two separated forms of process, but are correlative to one another. This, in turn, should allow me to clarify the ontological condition envisaged by Whitehead for the "total subject". In order to support in a conclusive way this thesis it is necessary, at this point, to study the concrete mode in which the present articulates in itself the other temporal dimensions, from the standpoint of the experiential act. Whitehead, in the passage above quoted, states that the single actual entities are not separated bodies, standing in succession. There is therefore a reciprocal presence of every actual entity in the others. Let us now consider the question from the point of view of temporality. 


\section{Concrescence and Transition Reciprocally Connected}

As we have seen, Whitehead distinguishes concrescence and transition in the way above considered. In some passages of Process and Reality he speaks of two types of process. ${ }^{12}$ But these two types are distinguished insofar as they represent the two modalities by which the process is constituted. They are in fact substantially identified with efficient and final causation, in turn reinterpreted by Whitehead in terms of perceptive experience. The model which Whitehead elaborates is thus the following: the new process of concrescence receives (in the active sense of this term) the determinations of what it must become from the world in which it arises. Therefore, that which, from the standpoint of the actual entities which constitute the given world of the new subject, represents a process of transition, i.e., efficient causation, becomes a process of concrescence, i.e., final causation, for the new process. Whether the process is a transition or a concrescence, it is a matter of perspective.

Thus, the relationality between actual entities is shown both in its modality and in its essential asymmetry. We should not forget, in fact, that the process of concrescence is intrinsically undetermined ${ }^{13}$ so that there is always only one direction for the process. It is indeed a matter of perspective, but the metaphysical generalisation must take into account every perspective. Therefore, that which appears, to an actual entity in phase of concrescence, as a type of process, appears as yet another type from the standpoint of the already 'concrete' actual entities (which obviously is possible only through an ex post facto analysis). In this way we can also illustrate the intrinsic solidarity of the world, which according to Whitehead plays such an important role for the comprehension of reality. ${ }^{14}$ Solidarity does not mean harmonic community, but an incessant process of separation and communication. For Whitehead it is clear that what usually is con-

12 See for example Whitehead 1978, 210: "[T]here are two kinds of fluency. One kind is the concrescence which, in Locke's language, is 'the real internal constitution of a particular existent'. The other kind is the transition from particular existent to particular existent. This transition, again in Locke's language, is the 'perpetually perishing' which is one aspect of the notion of time; and in another aspect the transition is the origination of the present in conformity with the 'power' of the past. [...] Concrescence moves towards its final cause, which is its subjective aim; transition is the vehicle of the efficient cause, which is the immortal past".

13 See Whitehead 1954, 242: "Time requires incompleteness. Each occasion is temporal because it is incomplete. Nor is there any system of occasions which is complete".

14 See Whitehead 1978, 167: "The universe is at once the multiplicity of res verae and the solidarity of res verae". On the topic see Nobo 1986. 
sidered as an individual, is in fact a dividual, a manifold community of internal subjects which are not necessarily all harmonically related to each other. ${ }^{15}$

It is possible, in this light, to further clarify the relationship between subject and superject: the subject is represented by the process of concrescence which effects the transposition from the publicity of the world, understood as the intercorporeal interrelation of actual entities, to the privacy of a subjective synthesis; but this activity is also the process of formation of the superject as the 'objectivation' of the very same process of concrescence by other subjectivities. Not that the concrescence first takes place and then gives rise to transition: to think in these terms means to see concrescence and transition as two distinct segments on a line, whereas the distinction drawn by Whitehead is to be understood in terms of the different perspective from which the process is considered, and therefore according to the different sense of being characterising the two modes. In fact there is no concrescence without transition and vice versa. The two processes are in a relation of codetermination which can also, in a certain sense, be understood through the biological-systemic concept of feedback. The temporality of this process is not linear, ${ }^{16}$ but is characterised by continuous anticipations and retro-actions. Past and future are present in the present, in their own way, as we have seen. ${ }^{17}$ Whitehead has tried to express this thesis with concepts which were still partially conditioned by the tradition he wants to abandon (reason why he coined so many neologisms), and yet he has stated in a sufficiently clear way what he wanted to say. For example, we possess in the following quotation a summary of the complex theme whose elements we are disentangling:

The various primary data and the concrescent feelings do not form a mere multiplicity. Their synthesis in the final unity of one actual entity is another fact of 'givenness'. The actual entity terminates its becoming in one complex feeling involving a completely determinate bond with every item in the universe, the bond being either a positive or a negative

15 This is why, according to Whitehead, there is a need for a superior principle of harmony, which he also calls the principle of limitation, and which in his Religion in the Making is historically considered in its various avatars. I cannot enter into this question, which exceeds by far my capacities. Nonetheless it seems clear to me that the major element of disagreement between Whitehead and Merleau-Ponty resides precisely in the fact that the former sees the necessity of postulating a transcendent element of order and harmony, while the latter would rather explain order and harmony as self-generating within process.

16 Whitehead 1954, 246: "Supersession is not a continuous process of becoming. If we try to combine the notions of supersession and continuity we are at once entangled in a vicious infinite regress".

17 See Whitehead 1978, 213 where Whitehead talks about the mutual interference between phases of the process. 
prehension. This termination is the 'satisfaction' of the actual entity. Thus, the addition of another component alters this synthetic 'givenness'. Any additional component is therefore contrary to this integral 'givenness' of the original. This principle may be illustrated by our visual perception of a picture. The pattern of colors is 'given' for us. But an extra patch of red does not constitute a mere addition; it alters the whole balance. Thus, in an actual entity the balanced unity of the total 'givenness' excludes anything that is not given. This is the doctrine of the emergent unity of the superject. An actual entity is to be conceived both as a subject presiding over its own immediacy of becoming, and a superject which is the atomic creature exercising its function of objective immortality. It has become a 'being'; and it belongs to the nature of every 'being' that it is a potential for every 'becoming'. [...] Returning to the correlation of 'givenness' and 'potentiality', we see that 'givenness' refers to 'potentiality', and 'potentiality' to 'givenness'; also we see that the completion of 'givenness' in actual fact converts the 'not-given' for that fact into 'impossibility' for that fact. The individuality of an actual entity involves an exclusive limitation. This element of 'exclusive limitation' is the definiteness essential for the synthetic unity of an actual entity. This synthetic unity forbids the notion of mere addition to the included elements (Whitehead 1978, 44-45).

It is thus possible to summarise what has been seen so far by stating that the overall processuality of reality must be distinguished into two interconnected modes, which express the solidarity between subjects and their reciprocal intercommunication, but at the same time their progressive distinction from one another. Each single process produces a synthetic perspective of the totality in which the process is arising, and this totality in its turn receives a shape from the process of concrescence which emerges from it. Each single experiential act is temporally limited, and its process gives rise to a further iteration of the overall processuality but does not amount to a higher synthesis. This processuality is anonymous and yet contains in itself the germs of a constant striving to overcome the anonymity. The question which must be posed with respect to this latter consideration is the following: why does this happen? Why the tension towards the overcoming of this anonymity? In order to do so we must finally analyse what Whitehead writes with respect to what is the normal concept of subjectivity of common sense. Human life rarely grasps itself in its continuous processuality and its plurality. Usually, each subject perceives itself, in the first place, as an individual. What is this 'individual' within the perspective of the metaphysics of process? 


\section{Succession and Temporality}

It is helpful to recall here that the subject Whitehead talks about is an incarnated subject, ${ }^{18}$ a non-un-extended corporeity, which in turn is not to be seen in terms of inert matter, but in terms of subjective body. Corporeity manifests itself immediately in temporal terms; it could be said that corporeity is intrinsically marked by temporality:

Further, our experiences of our various bodily parts are primarily perceptions of them as reasons for 'projected' sensa: the hand is the reason for the projected touch-sensum, the eye is the reason for the projected sight-sensum. Our bodily experience is primarily an experience of the dependence of presentational immediacy upon causal efficacy. Hume's doctrine inverts this relationship by making causal efficacy, as an experience, dependent upon presentational immediacy. This doctrine, whatever be its merits, is not based upon any appeal to experience (Whitehead 1978, 176).

The bodily subject is a subject because it is a perceiving body. By inverting the relation of cause and effect instituted by Empiricism, by reason of its paradoxical intellectualism, ${ }^{19}$ the philosophy of process shows in what sense corporeity means in the first place that bodily experience possesses a structure of its own, irreducible to the primacy of consciousness, which it is the task of philos-

18 The notion of dipolarity, used by Whitehead to characterise the way in which the subject perceives, is precisely meant to express this perspective. Instead of opposing mind and matter, which is the duality of substances Whitehead so often reproaches Descartes with, Whitehead says that mind and matter are to be seen together, or rather, that mind and matter are to be reconceived in terms of the inner dipolarity characterising each single actual entity as a "drop of experience". Each drop of experience is therefore intrinsically one, although dipolar, that is, dual. There is no room in this work to attempt a comparison between Merleau-Ponty and Whitehead on this subject, but I hope to show in another place that the notion of dimension worked out by Merleau-Ponty in VI (according to which each fact shows its dimensionality and each dimension retains an element of facticity) can help to understand in what sense experience is, in Whitehead's perspective, one (i.e., not divided into two substantial modes) and dual.

19 See for example Whitehead 1978, 141: "Hume and Locke, with the over-intellectualist bias prevalent among philosophers, assume that emotional feelings are necessarily derivative from sensations. This is conspicuously not the case; the correlation between such feelings and sensations is on the whole a secondary effect. Emotions conspicuously brush aside sensations and fasten upon the 'particular' objects to which-in Locke's phrase-certain 'ideas' are 'determined'. The confinement of our prehension of other actual entities to the mediation of private sensations is pure myth. The converse doctrine is nearer the truth: the more primitive mode of objectification is via emotional tone, and only in exceptional organisms does objectification, via sensation, supervene with any effectiveness". 
ophy to acknowledge in order to straighten an upside-down picture of experience. Thus, subjectivity is synonymous with temporality and affectivity. Whitehead writes:

The 'causal feeling' according to that [Hume's] doctrine arises from the long association of well-marked presentations of sensa, one precedent to the other. It would seem therefore that inhibitions of sensa, given in presentational immediacy, should be accompanied by a corresponding absence of 'causal feeling'; for the explanation of how there is 'causal feeling' presupposes the well-marked familiar sensa, in presentational immediacy. Unfortunately, the contrary is the case. An inhibition of familiar sensa is very apt to leave us a prey to vague terrors respecting a circumambient world of causal operations. In the dark there are vague presences, doubtfully feared; in the silence, the irresistible causal efficacy of nature presses itself upon us; in the vagueness of the low hum of insects in an August woodland, the inflow into ourselves of feelings from enveloping nature overwhelms us; in the dim consciousness of half-sleep, the presentations of sense fade away, and we are left with the vague feeling of influences from vague things around us. It is quite untrue that the feelings of various types of influences are dependent upon the familiarity of well-marked sensa in immediate presentment. Every way of omitting the sensa still leaves us a prey to vague feelings of influence. Such feelings, divorced from immediate sensa, are pleasant, or unpleasant, according to the mood; but they are always vague as to spatial and temporal definition, though their explicit dominance in experience may be heightened in the absence of sensa (Whitehead 1978, 176).

From the standpoint of the problem that we are considering in this paper, that is, the temporal side, it is particularly important to investigate the relationship between affectivity and temporality. It is in fact from this perspective that we can hope to bring to the fore the meaning of Whitehead's conception of the succession of actual entities seen as the origin of the enduring subjectivity. We have seen above that the structure of the single experiential process has two faces. This structure does not depend on some decision, but it appears through description. In other words, the solidarity between actual entities is not an ethical but ontological structure (although it bears ethical meanings). This explains the meaning of Whitehead's concept of succession. The succession of actual entities as such is given, it is the structure proper to the way in which the subjects manifest themselves. But in itself, it does not grant that the subject emerging in each single process can maintain itself and thus gives rise to a structured subjectivity. In other words, succession is a necessary but not a sufficient condition in order for a true subject to be given; on the contrary, in itself the temporal succession is more a matter of dispersion and loss than of maintenance and evolution. 


\title{
9 Mutual Sensitivity
}

The fundamental element to be investigated is what Whitehead calls mutual sensitivity between actual entities. Once again, it must be recalled that the structural definition of actual entity is the fact of its being the multiplicity of the world as given in perspective: "it will be presupposed that all entities or factors in the universe are essentially relevant to each other's existence” (Whitehead 1954, 248). The connection between actual entities is thus equivalent to their ontological essence. To speak of an actual entity in isolation is a nonsense, and this makes clear how the concept of actual entity cannot be understood in terms of atoms of reality except in a metaphorical sense. An actual entity thus reflects the communitarian structure of which it is part. As such, however, this consideration does not imply any particular type of privileged order. Whitehead insists very clearly on this aspect in the following passage:

\begin{abstract}
The general common function exhibited by any group of actual occasions is that of mutual immanence. In Platonic language, this is the function of belonging to a common Receptacle. If the group be considered merely in respect to this basic property of mutual immanence, however otherwise lacking in common relevance, then-conceived as exemplifying this general connectedness-the group is termed a Nexus. Thus, the term Nexus does not presuppose any special type of order, nor does it presuppose any order at all pervading its members other than the general metaphysical obligation of mutual immanence. But, in fact, the teleology of the Universe, with its aim at intensity and variety, produces epochs with various types of order dominating subordinate nexus interwoven with each other. A nexus can spread itself both spatially and temporally. In other words, it can include sets of occasions which are contemporary with each other, and it can include sets which are relatively past and future (Whitehead 1967, 201-202).
\end{abstract}

Thus, each actual entity structurally connects itself to other actual entities, nor could it be otherwise, since, as Whitehead underlines in this passage, this is an ontological character of the actual entity and not something an actual entity, more or less consciously, decides to be. The structures to which the connections between actual entities give rise are of several kinds and different complexity. Their unique common trait is their originating a temporally extended structure:

Any set of actual occasions are united by the mutual immanence of occasions, each in the other. To the extent that they are united they mutually constrain each other. Evidently this mutual immanence and constraint of a pair of occasions is not in general a symmetric relation. For, apart from contemporaries, one occasion will be in the future of the other. Thus, the earlier will be immanent in the later according to the mode of efficient causality, and the later in the earlier according to the mode of anticipation, as explained above. Any set of 
occasions, conceived as thus combined into a unity, will be termed a nexus (Whitehead 1967, 197).

This is the general structural datum, upon which the differentiation between different types of society supervenes. The dominant general characteristic of societies is that they do not have a pre-established temporal order. Whitehead is here describing the intersubjective intercorporeal community in terms of the absence of the particular order which is proper to conscious experience. What can be said, in order to conclude, is that Whitehead explicitly declares that there is no temporal order intrinsically proper to the societies in general. More precisely, Whitehead excludes the presence of the linear form of temporality proper to normal, i.e., conscious, human experience. It is then possible to assume that the emergence of an enduring subjectivity through the structuration of the actual entities might be connected to the emergence of a linear type of temporality.

\section{References}

Bergson, Henri (1912), Creative Evolution, Holt: New York.

Nobo, George L. (1986), Whitehead's Metaphysics of Extension and Solidarity, SUNY Press: Albany.

Russell, Bertrand (1996), History of Western Philosophy, Routledge: New York. Whitehead, Alfred N. (1920), The Concept of Nature, Cambridge University Press: Cambridge. Whitehead, Alfred N. (1954), The Interpretation of Science, The Bobbs-Merrill Co., Inc: New York.

Whitehead, Alfred N. (1967), Adventures of Ideas, The Free Press: New York. Whitehead, Alfred N. (1968), Modes of Thought, The Free Press: New York. Whitehead, Alfred N. (1978), Process and Reality, The Free Press: New York. Whitehead, Alfred N. (1985a), Science and the Modern World, Free Association Books: London.

Whitehead, Alfred N. (1985b), Symbolism, its meaning and effect, Cambridge University Press: New York. 